\title{
FORMULASI OBAT KUMUR MINYAK ATSIRI KULIT BUAH JERUK KALAMANSI (Citrus microcarpa Bunge)
}

\author{
Nabilah $^{1}$, Citra Yuliyanda Pardilawati ${ }^{2}$, Ika Savitri ${ }^{3}$ \\ ${ }^{1}$ Alumni STIK Siti Khadijah \\ ${ }^{2,3}$ Dosen STIK Siti Khadijah Palembang \\ Email : bilanabilah1@gmail.com \\ citra.yuliyanda@gmail.com \\ Ikasavitri41@gmail.com
}

\begin{abstract}
ABSTRAK
Masalah utama kesehatan gigi dan mulut yang paling sering terjadi ialah karies gigi dan plak. Karies gigi dan plak dapat disebabkan berbagai faktor diantaranya adalah karbohidrat dan glukosa, mikroorganisme dan air ludah, permukaan dan bentuk gigi salah satu pencegah maupun mengatasi hal tersebut dengan cara menggunakan obat kumur. Obat kumur digunakan karena kemampuannya sangat efektif menjangkau tempat yang sulit dibersihkan dengan sikat gigi, dapat mencegah pembentukan plak, menghilangkan bau mulut yang tidak sedap, menyegarkan nafas dan juga sebagai terapi untuk pencegahan terhadap karies gigi. Penelitian yang dilakukan adalah penelitian deskriptif. Kulit buah jeruk kalamansi (Citrus microcarpa Bunge) setelah dilakukan proses pengeringan didapatkan 500mg, selanjutnya timbang simplisia sebanyak 200gram untuk dilakukan metode destilasi. Setelah di destilasi, dilakukan evaluasi sediaan meliputi pengamatan organoleptis, pemeriksaan $\mathrm{pH}$, dan pemeriksaan viskositas dengan formula 1 PEG-40 2,5ml dan sorbitol 100ml, formula 2 PEG-40 $5 \mathrm{ml}$ dan sorbitol 150ml dan formula 3 PEG-40 $10 \mathrm{ml}$ dan sorbitol $200 \mathrm{ml}$.
\end{abstract}

\begin{abstract}
The most common dental and oral health problems are dental caries and plaque. Dental caries and plaque can be caused by various factors, including carbohydrates and glucose, microorganisms and saliva, the surface and shape of the teeth as one of the prevention and control of this by using mouthwash. Mouthwash is used because of its very effective ability to reach places that are difficult to clean with a toothbrush, it can prevent plaque formation, eliminate bad breath, freshen breath and also as a therapy for the prevention of dental caries. The research conducted is descriptive research. Kalamansi orange fruit peel (Citrus microcarpa Bunge) after the drying process obtained $500 \mathrm{mg}$, then weighed 200 grams of simplicia for the distillation method. After distillation, evaluation of the preparation includes organoleptic observation, $p H$ examination, and viscosity examination with formula 1 PEG-40 $2.5 \mathrm{ml}$ and sorbitol $100 \mathrm{ml}$, formula $2 \mathrm{PEG}-405 \mathrm{ml}$ and sorbitol $150 \mathrm{ml}$ and formula 3 PEG-40 $10 \mathrm{ml}$ and sorbitol $200 \mathrm{ml}$.
\end{abstract}

Keywords : Citrus microcarpa Bunge, Mouthwash

Bibliography : 19 (Year 2000-2019) 


\section{PENDAHULUAN}

\section{A. Latar Belakang}

Pengobatan tradisional menggunakan bahan alam telah dilakukan sejak dahulu kala di Indonesia. Bahan alam digunakan sebagai media pengobatan tradisional oleh masyarakat Indonesia karena banyaknya tumbuhan yang berkhasiat sebagai obat, baik berdasarkan kepercayaan empiris yang bersifat turun menurun maupun yang telah ditemukan oleh para ilmuwan. Salah satu penyakit yang sering dialami oleh masyarakat adalah infeksi. Infeksi merupakan salah satu penyakit yang disebabkan oleh bakteri dan diobati dengan penggunaan antibiotik. Beberapa bakteri yang dapat menyebabkan infeksi anatara lain Streptococcus mutans, Salmonella thypi, Bacillus subtilis dan scherichia coli (Radji, 2011).

Kesehatan gigi dan mulut dapat mempengaruhi kesehatan tubuh secara menyeluruh. Masalah utama kesehatan gigi dan mulut yang paling sering terjadi ialah karies gigi dan plak . Karies gigi adalah penyakit jaringan gigi yang ditandai dengan kerusakan jaringan, dimulai dari permukaan gigi mulai dari email, dentin, dan meluas ke arah pulpa. Karies gigi dapat disebabkan berbagai faktor diantaranya adalah karbohidrat dan glukosa, mikroorganisme dan air ludah, permukaan dan bentuk gigi, serta dua bakteri yang paling umum bertanggung jawab untuk gigi berlubang adalah Streptococcus mutans dan lactobacillus.

Menurut data survei World Health Organization tercatat bahwa di seluruh dunia 60-90\% anak mengalami karies gigi. Prevalensi tertinggi karies gigi pada anakanak di Amerika dan kawasan Eropa, indeks agak rendah dari Mediterania Timur dan wilayah barat pasifik, sementara prevalensi terendah adalah Asia Tenggara dan Afrika.

Menurut Riskesdas (2018) tentang kesehatan gigi dan mulut mencatat proporsi masalah gigi dan mulut sebesar 57,6\% dan mendapatkan pelayanan dari tenaga medis gigi sebesar 10,2\%. Adapun proporsi perilaku menyikat gigi dengan benar sebesar $2,8 \%$.

Data menunjukkan presentase perilaku benar menyikat gigi usia 10-14 tahun yang menggosok gigi setiap hari sebanyak 90,3\%, menggosok gigi saat mandi pagi/sore sebesar $86,1 \%$, menggosok gigi sesudah makan pagi $9,6 \%$, sesudah bangun pagi $27,4 \%$, dan sebelum tidur malam $17 \%$ dan tidak benar $98,7 \%$. data yang menunjukkan persentase penduduk usia 10-14 tahun yang berperilaku benar menyikat gigi sebesar $4,7 \%$ dan tidak 95,3\% (Linda.S, 2017)

Bakteri yang ada di plak gigi adalah Streptococcus mutans. Streptococcus mutans merupakan bakteri kariogenik yang mampu melekat di permukaan gigi, meningkatkan kumpulan plak, menghasilkan glukan dan polisakarida yang menyebabkan demineralisasi email gigi (Ervianingsih et.al, 2017) ada dua upaya untuk mencegah masalah kesehatan gigi dan mulut yaitu dengan cara mekanisme maupun kimiawi. Secara mekanis dapat meliputi penyikatan gigi dan penggunaan benang gigi. Pembersihan gigi secara mekanisme merupakan salah satu cara yang cukup efektif dalam pengendalian plak dan inflamasi gingiva ( Oktavani et.al, 2015).

Plak juga merupakan kumpulan bakteri yang terikat dalam suatu matriks organik dan melekat erat pada permukaan gigi. Plak terdiri atas mikroorganisme yang berkembang biak dalam suatu matriks interseluler yang berupa lengketan bakteri 
beserta produk-produk bakteri. Mekanisme terjadinya plak adalah terbentuknya acquired pelicle pada permukaan gigi yang berwarna transparan, kemudian bakteri akan menempel dan berpoliferasi sehingga warna akan berubah menjadi kekuningan. Ada banyak cara yang dilakukan untuk mencegah plak dan karies gigi, salah satunya penggunaan obat kumur. Obat kumur digunakan karena kemampuannya sangat efektif menjangkau tempat yang sulit dibersihkan dengan sikat gigi dan dapat mencegah pembentukan plak. Obat kumur merupakan salah satu alternatif terbaik untuk mengurangi plak pada gigi, untuk menghilangkan bau mulut yang tidak sedap, menyegarkan nafas, juga sebagai terapi untuk pencegahan terhadap

karies gigi (Lulun, Z.F., 2012).

Saat ini para peneliti banyak melakukan penelitian pada tanamantanaman obat sebagai alternatif bahan kimia yang sudah ada. Salah satu tumbuhan yang dapat digunakan sebagai obat dan memiliki aktivitas antibakteri adalah kulit buah Jeruk kalamansi (Citrus microcarpa Bunge). Tumbuhan ini mempunyai khasiat sebagai antibakteri (Rahmawati, 2008). Citrus microcarpa Bunge memiki kandungan senyawa fenolik. Flavonoid adalah kelompok fenolik pada tumbuhan yang bertanggung jawab atas aktivitas antimikroba dimana dapat menghambat sintesis asam nukleat, fungsi membran sitoplasma, dan metabolisme energi (Sumarno, 2019). Sumarno (2019) menyatakan bahwa sejumlah tanaman obat yang mengandung flavonoid memiliki aktivitas antioksidan, antibakteri, antivirus, antiradang dan antikanker.

Berdasarkan penelitian yang dilakukan oleh Quyet et.al (2019) kandungan minyak atsiri kulit buah Jeruk kalamansi yaitu limonene, $\beta$-mirsen, $\alpha$ - pinen, sikloheksana, dan $\alpha$-cubeben. Senyawa $\alpha$-pinen dan $\beta$-pinen merupakan senyawa terpenoid yang dikenal mempunyai efek antimkroba (Senthilkumar et.al, 2009).

Berdasarkan penelitian Muthia rachma (2010) dilakukan formulasi terhadap obat kumur yang mengandung minyak atsiri Curcuma xanthorriza sebagai antibakteri terhadap salah satu bakteri penyebab bau mulut. Serta menguji stabilitas fisik sediaan pada penyimpanan suhu rendah $\left(4^{\circ} \mathrm{C} \pm 2^{\circ} \mathrm{C}\right)$, suhu kamar $\left(28^{\circ} \mathrm{C}\right.$ $\left.\pm 2^{\circ} \mathrm{C}\right)$, dan suhu tinggi $\left(40^{\circ} \mathrm{C} \pm 2^{\circ} \mathrm{C}\right)$.

\section{B. Rumusan Masalah}

Masih tingginya proporsi masalah gigi dan mulut masyarakat Indonesia yang sebesar $57,6 \%$. Cara untuk mencegah plak dan karies gigi salah satunya adalah dengan berkumur obat kumur yang memiliki aktivitas antibakteri yaitu minyak atsiri kulit buah jeruk kalamansi (Citrus microcarpa Bunge)

\section{Tujuan Penelitian}

Diketahui formulasi obat kumur minyak atsiri kulit buah Jeruk kalamansi (Citrus microcarpa Bunge).

\section{Manfaat Penelitian}

Hasil penelitian ini dapat memberikan informasi mengenai formulasi kulit buah Jeruk Kalamansi (Citrus microcarpa Bunge) sebagai obat kumur dalam mencegah terjadinya plak dan karies gigi. Dan dapat menjadi referensi tambahan bagi penelitian selanjutnya dengan metode dan formulasi yang berbeda.

\section{METODOLOGI PENELITIAN}

\section{A. Desain Penelitian}

Jenis penelitian yang digunakan adalah deskriptif, untuk mengetahui formulasi sediaan obat kumur minyak atsiri kulit buah Jeruk kalamansi (Citrus microcarpa Bunge) yang bermutu baik. 


\section{B. Populasi dan Sampel}

Populasi yang digunakan dalam penelitian ini adalah tanaman jeruk kalamansi (Citrus microcarpa Bunge) yang diperoleh dari pasar tradisional, Sumatera Selatan. Yang menjadi sampel dalam penelitian ini adalah kulit buah Jeruk kalamansi yang berwarna hijau dengan tekstur mengkilap dan masih segar diambil secara acak. Penelitian ini dilakukan di Laboratorium STIK Siti Khadijah Palembang dari bulan April sampai Juli 2020.

\section{Pengumpulan dan Pengolahan Data}

Penelitian ini menggunakan data primer yang diperoleh melalui Evaluasi Sediaan Obat Kumur untuk mengetahui kestabilan dari sediaan obat kumur yang telah dibuat. Evaluasi pengamatan yang dilakukan meliputi : Uji Organoleptis, Pengukuran PH dan Pengukuran Viskositas.

Alur penelitian yang dilakukan adalah dengan menyiapakan kulit buah Jeruk Kalamansi (Citrus microcarpa Bunge) sebanyak $10 \mathrm{Kg}$, kemudian dikeringkan sampai dapat $200 \mathrm{mg}$ kulit jeruk kering lalu dilakukan destilasi agar menghasilkan minyak atsiri sebanyak $50 \mathrm{ml}$. Pembuatan fase larut air dengan dilarutkan bahan- bahan larut air seperti kalsium laktat, dan kalsium tiosianat, sampai homogen.

Bahan yang kurang larut dalam air (asam benzoate, minyak atsiri, BHT) dilarutkan dengan oleum menthe. Lalu diemulsikan dengan PEG-40. Bahan yang mudah larut air ditambahkan sedikit demi sedikit kedalam larutan yang telah diemulsi. Lalu ditambahkan sorbitol aduk sampai homogen. $\mathrm{Na}$ benzoat dilarutkan dengan aquadest kemudian ditambahkan dengan bahan tersebut. Langkah terakhir dilakukan evaluasi sediaan obat kumur.

\section{Instrumen Penelitian}

Peralatan yang digunakan dalam penelitian ini adalah timbangan analitik, $\mathrm{pH}$ meter, gelas ukur, lemari pendingin, alatalat gelas, pipet, penangas air, viskometer brookfield, spatula, aluminium foil, 1 set alat destilasi penyuling uap skala laboratorium dan alat-alat yang biasa dipergunakan dalam Laboratorium.

Bahan uji yang digunakan dalam penelitian ini adalah minyak atsiri kulit buah Jeruk kalamansi (Citrus microcarpa Bunge), bahan lain yang digunakan dalam penelitian ini adalah PEG-40, Aquadest, Asam Benzoat, Natrium Benzoat, Kalsium Laktat, Kalsium Tiosianat, Sorbitol, Butil Hidroksi Toluen (BHT), Oleum Menthe, dan Menthol.

Table 1.1 Formulasi obat minyak atsiri ekstrak kulit buah Jeruk kalamansi (Citrus microcarpa Bunge)

\begin{tabular}{|c|c|c|c|c|}
\hline \multirow{2}{*}{ Bahan } & \multirow{2}{*}{ Fungsi } & \multicolumn{3}{|c|}{ Jumlah Bahan } \\
\cline { 3 - 5 } & & F1 & F2 & F3 \\
\hline Minyak atsiri kulit buah Jeruk kalamansi & Zat aktif & $2,5 \mathrm{ml}$ & $2,5 \mathrm{ml}$ & $2,5 \mathrm{ml}$ \\
\hline PEG-40 & Emulsifier & $2,5 \mathrm{ml}$ & $5 \mathrm{ml}$ & $10 \mathrm{ml}$ \\
\hline Oleum Menthe & Aroma & $30 \mathrm{tetes}$ & 30 tetes & 30 tetes \\
\hline Asam Benzoat & Dapar & $25 \mathrm{mg}$ & $25 \mathrm{mg}$ & $25 \mathrm{mg}$ \\
\hline Natrium Benzoat & Pengawet & $10 \mathrm{mg}$ & $10 \mathrm{mg}$ & $10 \mathrm{mg}$ \\
\hline Kalsium Laktat & Pengental & $250 \mathrm{mg}$ & $250 \mathrm{mg}$ & $250 \mathrm{mg}$ \\
\hline Sorbitol & Humektan & $100 \mathrm{ml}$ & $150 \mathrm{ml}$ & $200 \mathrm{ml}$ \\
\hline Butil Hidroksi Toluen & Antioksidan & $1 \mathrm{mg}$ & $1 \mathrm{mg}$ & $1 \mathrm{mg}$ \\
\hline Menthol & Penyedap & $25 \mathrm{mg}$ & $25 \mathrm{mg}$ & $25 \mathrm{mg}$ \\
\hline Aquadest & Pelarut & $\begin{array}{c}\text { Ad } 500 \\
\mathrm{ml}\end{array}$ & $\begin{array}{c}\text { Ad } 500 \\
\mathrm{ml}\end{array}$ & $\begin{array}{c}\text { Ad } 500 \\
\mathrm{ml}\end{array}$ \\
\hline
\end{tabular}

Volume X No. 2 Desember 2020 Hal - 119 


\section{HASIL PENELITIAN DAN PEMBAHASAN}

Uji Mutu obat kumur minyak atsiri kulit buah jeruk kalamansi, Hasil evaluasi sediaan meliputi :

Uji organoleptis dilakukan dengan pengamatan oleh peneliti selama 7 hari mulai dari H-0 sampai H-6 dengan mengamati warna, aroma dan rasa dari sediaan obat kumur. Sifat organoleptis akan mempengaruhi minat seseorang untuk mengkonsumsi obat kumur, oleh karena itu hendaknya sediaan obat kumur yang di hasilkan memiliki warna yang cerah, aroma yang menyenangkan dan rasa yang menarik atau segar.
Berdasarkan hasil uji organoleptis formulasi obat kumur minyak atsiri kulit jeruk kalamansi terbaik adalah formula 3 . Sediaan berbentuk obat kumur berwarna kuning dan berbau khas. Sedangkan pada formula 1 dan formula 2 memiliki rasa dan warna yang agak berbeda dibanding formula 3, hal ini disebabkan jumlah pemberian PEG-40 dan sorbitol yang berbeda. Rasa pada formula 1 dan formula 2 sama seperti formula 3 yakni beraroma khas.

Hasil terhadap organoleptis obat kumur minyak atsiri kulit buah jeruk kalamansi pada tabel 1.2.

Tabel 1.2 Hasil Uji terhadap organoleptis

\begin{tabular}{|c|c|c|c|c|c|c|c|c|}
\hline \multirow{2}{*}{ Formula } & \multirow{2}{*}{ Parameter } & \multicolumn{7}{|c|}{ Waktu Pengujian (Hari) } \\
\hline & & $\mathbf{0}$ & 1 & 2 & 3 & 4 & 5 & 6 \\
\hline \multirow{3}{*}{1} & Warna & $\begin{array}{l}\text { Kuning } \\
\text { Keruh }\end{array}$ & $\begin{array}{l}\text { Kuning } \\
\text { Keruh }\end{array}$ & $\begin{array}{l}\text { Kuning } \\
\text { Keruh }\end{array}$ & $\begin{array}{l}\text { Kuning } \\
\text { Keruh }\end{array}$ & $\begin{array}{l}\text { Kuning } \\
\text { Keruh }\end{array}$ & $\begin{array}{l}\text { Kuning } \\
\text { Keruh }\end{array}$ & $\begin{array}{l}\text { Kuning } \\
\text { Keruh }\end{array}$ \\
\hline & Aroma & $\begin{array}{l}\text { Aroma } \\
\text { Khas }\end{array}$ & $\begin{array}{c}\text { Aroma } \\
\text { Khas }\end{array}$ & $\begin{array}{l}\text { Aroma } \\
\text { Khas }\end{array}$ & $\begin{array}{l}\text { Aroma } \\
\text { Khas }\end{array}$ & $\begin{array}{c}\text { Aroma } \\
\text { Khas }\end{array}$ & $\begin{array}{c}\text { Aroma } \\
\text { Khas }\end{array}$ & $\begin{array}{c}\text { Aroma } \\
\text { Khas }\end{array}$ \\
\hline & Rasa & $\begin{array}{l}\text { Manis } \\
\text { \& Mint }\end{array}$ & $\begin{array}{l}\text { Manis } \\
\text { \& Mint }\end{array}$ & $\begin{array}{l}\text { Manis } \\
\text { \& Mint }\end{array}$ & $\begin{array}{l}\text { Manis } \\
\& \text { Mint }\end{array}$ & $\begin{array}{l}\text { Manis \& } \\
\text { Mint }\end{array}$ & $\begin{array}{l}\text { Manis } \\
\text { \& Mint }\end{array}$ & $\begin{array}{l}\text { Manis } \\
\text { \& Mint }\end{array}$ \\
\hline \multirow{3}{*}{2} & Warna & $\begin{array}{l}\text { Kuning } \\
\text { sedikit } \\
\text { bening }\end{array}$ & $\begin{array}{l}\text { Kuning } \\
\text { sedikit } \\
\text { bening }\end{array}$ & $\begin{array}{l}\text { Kuning } \\
\text { sedikit } \\
\text { bening }\end{array}$ & $\begin{array}{l}\text { Kuning } \\
\text { sedikit } \\
\text { bening }\end{array}$ & $\begin{array}{l}\text { Kuning } \\
\text { sedikit } \\
\text { bening }\end{array}$ & $\begin{array}{l}\text { Kuning } \\
\text { sedikit } \\
\text { bening }\end{array}$ & $\begin{array}{l}\text { Kuning } \\
\text { sedikit } \\
\text { bening }\end{array}$ \\
\hline & Aroma & $\begin{array}{l}\text { Aroma } \\
\text { Khas }\end{array}$ & $\begin{array}{l}\text { Aroma } \\
\text { Khas }\end{array}$ & $\begin{array}{l}\text { Aroma } \\
\text { Khas }\end{array}$ & $\begin{array}{l}\text { Aroma } \\
\text { Khas }\end{array}$ & $\begin{array}{l}\text { Aroma } \\
\text { Khas }\end{array}$ & $\begin{array}{l}\text { Aroma } \\
\text { Khas }\end{array}$ & $\begin{array}{l}\text { Aroma } \\
\text { Khas }\end{array}$ \\
\hline & Rasa & $\begin{array}{l}\text { Manis } \\
\& \text { Mint }\end{array}$ & $\begin{array}{l}\text { Manis } \\
\text { \& Mint }\end{array}$ & $\begin{array}{l}\text { Manis } \\
\text { \& Mint }\end{array}$ & $\begin{array}{l}\text { Manis } \\
\text { \& Mint }\end{array}$ & $\begin{array}{l}\text { Manis \& } \\
\text { Mint }\end{array}$ & $\begin{array}{l}\text { Manis } \\
\text { \& Mint }\end{array}$ & $\begin{array}{l}\text { Manis } \\
\text { \& Mint }\end{array}$ \\
\hline \multirow{3}{*}{3} & Warna & $\begin{array}{l}\text { Kuning } \\
\text { Bening }\end{array}$ & $\begin{array}{l}\text { Kuning } \\
\text { Bening }\end{array}$ & $\begin{array}{l}\text { Kuning } \\
\text { Bening }\end{array}$ & $\begin{array}{l}\text { Kuning } \\
\text { Bening }\end{array}$ & $\begin{array}{l}\text { Kuning } \\
\text { Bening }\end{array}$ & $\begin{array}{l}\text { Kuning } \\
\text { Bening }\end{array}$ & $\begin{array}{l}\text { Kuning } \\
\text { Bening }\end{array}$ \\
\hline & Aroma & $\begin{array}{l}\text { Aroma } \\
\text { Khas }\end{array}$ & $\begin{array}{c}\text { Aroma } \\
\text { Khas }\end{array}$ & $\begin{array}{l}\text { Aroma } \\
\text { Khas }\end{array}$ & $\begin{array}{l}\text { Aroma } \\
\text { Khas }\end{array}$ & $\begin{array}{l}\text { Aroma } \\
\text { Khas }\end{array}$ & $\begin{array}{l}\text { Aroma } \\
\text { Khas }\end{array}$ & $\begin{array}{c}\text { Aroma } \\
\text { Khas }\end{array}$ \\
\hline & Rasa & Manis & Manis & Manis & Manis & Manis & Manis & Manis \\
\hline
\end{tabular}

Keterangan :

F1 : Obat kumur PEG-40 2,5ml dan Sorbitol 100ml

F2 : Obat kumur PEG-40 5ml dan Sorbitol $150 \mathrm{ml}$

F3 : Obat kumur PEG-40 10ml dan Sorbitol 200ml

Dari hasil pengamatan peneliti terhadap organoleptis sediaan obat kumur menunjukkan bahwa warna dari formula 1 kuning keruh, warna dari formula ke 2 sedikit bening, sedangkan formula ke 3 lebih bening. Uji terhadap rasa terdapat perbedaan antara obat 
kumur penggunaan PEG-40 dan sorbitol yang lebih sedikit

sampai penggunaan PEG-40 dan sorbitol yang lebih banyak. Formula 1 dan 2 didominasi oleh rasa manis dan mint sedang kan formula 3 memunculkan rasa manis yang lebih terasa. Dari segi warna tidak terjadi perbedaan yang mencolok. Pengujian $\mathrm{pH}$ dilakukan untuk mengetahui tingkat keasaman dan kebasaan dari sediaan agar tidak terjadi reaksi yang tidak diinginkan didalam mulut. Pengukuran $\mathrm{pH}$ dilakukan dengan $\mathrm{pH}$ meter. Hasil penguji $\mathrm{pH}$ dapat dilihat pada tabel 1.3. Uji pH dilakukan untuk melihat tingkat keasaman sediaan obat kumur untuk menjamin agar sediaan obat kumur tidak akan mengiritasi bagian mulut. $\mathrm{pH}$ sediaan yang memenuhi standar yaitu dengan range 6,0 - 7,5. Pada uji $\mathrm{pH}$ sediaan obat kumur pada masingmasing memiliki PH yang masih dalam standar sediaan $\mathrm{pH}$ sehingga masih aman dan pada masing-masing memiliki $\mathrm{pH}$ yang masih tidak mengiritasi mukosa mulut.

\section{Tabel 1.3 Hasil Uji terhadap pemeriksaan pH}

\begin{tabular}{|c|c|c|c|}
\hline \multirow{2}{*}{$\begin{array}{c}\text { Waktu } \\
\text { Pengamatan (Hari) }\end{array}$} & \multicolumn{3}{|c|}{ Formula } \\
\cline { 2 - 4 } & Formula 1 & Formula 2 & Formula 3 \\
\hline 0 & 6,8 & 6,6 & 6,7 \\
\hline 1 & 6,8 & 6,7 & 6,5 \\
\hline 2 & 6,7 & 6,6 & 6,6 \\
\hline 3 & 6,7 & 6,8 & 6,8 \\
\hline 4 & 6,7 & 6,7 & 6,7 \\
\hline 5 & 6,6 & 6,9 & 6,8 \\
\hline 6 & 6,5 & 6,7 & 7,0 \\
\hline
\end{tabular}

\section{Keterangan :}

F1 : Obat kumur PEG-40 2,5ml dan Sorbitol 100ml

F2 : Obat kumur PEG-40 5ml dan Sorbitol $150 \mathrm{ml}$

F3 : Obat kumur PEG-40 10ml dan Sorbitol 200ml

Nilai $\mathrm{pH}$ pada tabel diatas menunjukkan adanya perbedaan $\mathrm{pH}$ dari setiap masing-masing formula. Semua formula dari H-0 sampai hari terakhir H-6 masih dalam rentang standar $\mathrm{pH}$ obat kumur yang sesuai dengan SNI yaitu 6,0 - 7,5 sehingga sediaan ini tidak mengiritasi mukosa mulut. Dapat di lihat Hasil uji terhadap $\mathrm{pH}$ tersebut menunjukkan bahwa sediaan obat kumur kulit jeruk kalamansi pada penelitian ini cenderung bersifat asam dengan ditunjukkan oleh nilai $\mathrm{pH}$ dibawah 7. Pengujian viskositas terhadap obat kumur kulit jeruk kalamansi dilakukan untuk mengetahui tingkat kekentalan obat kumur. Pengujian viskositas menunjukan bahwa terjadi perbedaan pada masingmasing sediaan. Pengujian viskositas dilakukan menggunakan viskometer brookfield.

Uji viskositas dilakukan dengan tujuan untuk mengetahui seberapa kental obat kumur yang dihasilkan. Jika suatu 
sediaan obat kumur terlalu kental maka dapat mengurangi kenyamanan pengguna saat menggunakannya karena akan terasa sangat tidak nyaman. Hasil uji viskositas obat kumur kulit jeruk kalamansi pada tabel 1.4

Tabel 1.4 Hasil Uji terhadap pemeriksaan viskositas

\begin{tabular}{|c|c|c|c|c|}
\hline \multirow{2}{*}{$\begin{array}{c}\text { Waktu } \\
\text { Pengamatan } \\
\text { (Hari) }\end{array}$} & Formula 1 & Formula 2 & Formula 3 & $\begin{array}{c}\text { Obat Kumur } \\
\text { Komersil }\end{array}$ \\
\cline { 2 - 5 } & 135 & 120 & 135 & 125 \\
\hline 0 & 140 & 135 & 145 & 140 \\
\hline 1 & 145 & 150 & 155 & 165 \\
\hline 2 & 154 & 179 & 165 & 170 \\
\hline 3 & 120 & 175 & 140 & 169 \\
\hline 4 & 135 & 140 & 154 & 165 \\
\hline 5 & 125 & 130 & 164 & 168 \\
\hline 6 & & & & \\
\hline
\end{tabular}

Keterangan :

F1 : Obat kumur PEG-40 2,5ml dan Sorbitol 100ml

F2 : Obat kumur PEG-40 $5 \mathrm{ml}$ dan Sorbitol $150 \mathrm{ml}$

F3 : Obat kumur PEG-40 10ml dan Sorbitol 200ml

Hasil pengujian viskositas sediaan obat kumur minyak atsiri kulit buah jeruk kalamansi diketahui bahwa setiap formula memiliki viskositas yang berbeda-beda. Perbedaan nilai viskositas tersebut disebabkan oleh konsentrasi PEG-40 dan sorbitol yang berbeda-beda pada masingmasing formula. Penurunan viskositas pada pengujian tiap formula disebabkan oleh faktor penyimpanan yakni suhu dan tekanan. Kenaikan suhu dapat menyebabkan viskositas menurun.

\section{Keterbatasan Peneliti}

Peneliti menyadari adanya keterbatasan penelitian baik dalam segi waktu maupun fasilitas yang di gunakan. Keterbatasan penelitian adalah kurang nya alat viskositas brookfield pada penelitian sehingga peneliti menggunakan viskositas uk-2.

\section{KESIMPULAN}

1. Obat kumur minyak atsiri kulit buah jeruk kalamansi (Citrus microcarpa Bunge) formula 1 memiliki bau khas, berwarna kuning keruh, nilai $\mathrm{pH}$ sesuai Standar Nasional Indonesia (SNI) dan viskositas yang signifikan dengan obat kumur yang di pasaran.

2. Obat kumur minyak atsiri kulit jeruk kalamansi (Citrus microcarpa Bunge) formula 2 memiliki bau khas, berwarna kuning sedikit bening, nilaipH susai Standar Nasional Indonesia (SNI) dan viskositas yang signifikan dengan obat kumur yang ada di pasaran. 
3. Obat kumur minyak atsiri kulit buah jeruk kalamansi (Citrus microcarpa Bunge) formula 3 memiliki bau khas, berwarna kuning bening, nilai $\mathrm{pH}$ sesuai dengan Standar Nasional Indonesia (SNI) dan viskositasnya yang signifikan dengan obat kumur yang di pasaran.

\section{SARAN}

Masyarakat memanfaatkan minyak atsiri kulit buah jeruk kalamansi (Citrus microcarpa Bunge) ini sebagai obat kumur yang dapat mencegah terjadinya flak dan karies gigi. Dan peneliti selanjutnya diharapkan dapat melakukan penelitian yang lebih mendalam terhadap formulasi sediaan obat kumur tersebut dengan metode true experiment agar didapat hasil yang signifikant dari manfaat sebagai obat kumur pencegah plak dan karies gigi.

\section{DAFTAR PUSTAKA}

Anonim. 2013. Pengertian Proses Destilasi. http://www.pengertian ahli.com

Cahyono, B., 2005. Budidaya Jeruk Mandarin. Yogyakarta : Yayasan Pustaka Nusantara.

Depkes RI. Farmakope Indonesia Edisi III. Jakarta : Depkes RI : 1979.

Depkes RI. Departemen Kesehatan Republik Indonesia. 2000. Parameter Standar Umum Ekstrak Tumbuhan Obat. Jakarta: Departemen Kesehatan Republik Indonesia.

Deza. O., Nurhamidah., Dewi. H., 2019. Uji Aktifitas Antibakteri Dadun Jruk Kalamansi (Citrusfortunella microcarpa) terhadap Bakteri staphylococcus aureus dan Escherichia coli.
Ervianingsih., \& Razak, A. 2017. Uji Daya Hambat Ekstrak Daun Kucai (Allium schoenoprasum L) Terhadap Pertumbuhan Streptococcus mutans. Jurnal Mandala Pharmacon Indonesia, 3 (2) Desember, pp 73-79.

Junaidi. A., 2011. Pengembangan Produk Unggulan Jeruk Kalamansi Kota Bengkulu dengan Pendekatan OVOP. Jurnal INFOKOP. (19).pp :163-183.

Jeanne Mervrayano., Rahmatini., Elizabeth. B., 2015. Perbandingan Efektifitas Obat Kumur yang Mengandung Chlorhexidine dengan Povidone Iodine terhadap Streptococcus.

Kindangen, G.D., Lolo, W. A., \& Yamlean, P.V.Y. 2018. Uji Aktivitas Antibakteri Minyak Atsiri Kulit Buah Jeruk Kalamansi (Citrus microcarpa Bunge). Terhadap Bakteri Staphylococcus aureus Dan Escherichia coli. Pharmacon, 7 (4) November

Khotimah, H., Anggraeni, E.W., \& Setianingsi, A. 2017. Karaterisasi Pengolahan Air Menggunakan Alat Destilasi. Jurnal Chermurgy, 1(2) Desember.

KNEPK (Komisi Nasional Etik Penelitian Kesehatan). 2007. Pedoman Nasional Etika Penelitian Kesehatan. Dep. Kes. Jakarta.

Linda. S., 2017. Gambaran Menyikat Gigi Terhadap Tingkat Kebersihan Gigi dan Mulut Pada Murid Kelas V di MIN 9 Kecamatan Ulee Kareng Kota Banda Aceh. Jurnal Biotik (5). pp : 149-156. 
Lulun. Z.F., 2012. Uji Aktivitas Antiseptik Sediaan Mouthwash yang di formulasikan dari Liofilisat Buah Belimbingan Wuluh (Averrhoa bilimbi L). Terhadap Bakteri Streptococcus mutans (skripsi). Jurusan Farmasi Fakultas Farmasi. Universitas Hasanuddin. Makassar.

Muthia, R,. 2010. Formulasi Sediaan Obat Kumur yang mengandung Minyak Atsiri Temulawak (Curcuma xanthorriza) sebagai Antibakteri Porphyromonas gingivalis Penyebab Bau Mulut.

Nuraini, 2011. Sinonim Tumbuhan. Sinonim Citrus mitis. Citrus Fortunella.

Oktaviani, V. 2015. Perbedaan Indeks Higiene Oral Dan pH Plak Kelompok Pemakai Dan Bukan Pemakai Pesawat Ortodonti Cekat. Skripsi. Semarang.

Fakultas Kedokteran. Universitas DiPonegoro.

Quyet, N.T.C., Ngan, T.T.K., Anh, P.N.Q., Anh, N.Q., Thi, N.T.N., Ngoc, T.T.L., Nhan, L.T.H., Truc, T.T., \& Phuong, L.T.B. Essential Oil Hydrodistillation Process From Vietnamese Calamondin (Ctrus microcarpa) Peels And GC/MS Analysis Of Essential Oil Components. Asian Journal Of Chemistry, 31 (11), Pp. 2585-2588.

Radji. M., 2011. Mikrobiologi. Buku kedokteran egc Jakarta.

Rahmawati, F,. 2008. Isolasi dan Karakteristik Senyawa (Colues Scutellarioides [L]

Benth) [Tesis] Institusi Pertanian Bogor. Bogor.
Riset Kesehatan Dasar. 2018. Kesehatan Gigi dan Mulut. Jakarta

Rowe. R. C., Skeskey, P.J., dan Quinn, M.E. 2009. Handbook Of Pharmaceutical Excipients. 6th Edition. London : Pharmaceutical Press.

Sirait, Lora Yusnita and Laili, Susanti and Devi. Silsia. 2018. Pemanfaatan Serbuk Kulit Buah Jeruk Kalamansi (Citrusfortunella microcarpa)sebagai Aroma Teh Hijau Bubuk. Undergraduated Thesis. Universitas Bengkulu.

Sumarno, Ayu Cahyani. 2019. Uji Aktivitas Antibakteri Akstrak, Fraksi nHeksan, Etil Asetat dan Air Kulit Buah Jeruk Kalamansi ( Citrus microcarpa)Terhadap Bakteri Staphylococcus aureus ATCC 25923 dan Escherchia coli ATCC 25922. Skripsi Thesis. Universitas Setia Budi.

Sumarni, N. B. Aji dan Solekan. 2008. Pengaruh Volume Air dan Berat Bahan Pada Penyulingan Minyak Atsiri. Jurnal Teknologi, Vol. 1, 2008: $\quad$ 83-88.

Susanto. 2007. Kesehatan Gigi dan Mulut. Jakarta : Sunda Kelapa Pustaka

Tarigan, R., 2016. Karies gigi. Jakarta : EGC World Health Organization. Recent Advances in Oral Health. Report of a WHO Expert Committee. WHO Technical Reports Series 1992. 
